BIOMEDICA

Vol. 4 , No. 3 y $4-1984$

\title{
REVISIONES
}

\section{SUBPOBLACIONES DE LINFOCITOS T.}

\author{
CLAUDIA PEÑA R. *
}

La función de los linfocitos era desconocida hasta que Gowans en 1965 los identificó como células importantes del sistema inmune (1). En una revisión hecha por Trowell en 1958 (2), hace sólo 25 años, los linfocitos eran considerados como células que poseían únicamente atributos negativos y que a pesar de haber sido estudiados durante aproximadamente cien años, no había podido asignárseles función alguna.

Una vez establecida la importancia de los linfocitos, se encontró que la respuesta inmune incluye interacciones complementarias de los linfocitos derivados de la médula ósea (linfocitos B) y los linfocitos derivados del timo (linfocitos T) (3). Los primeros trabajos realizados sobre los linfocitos $T$, concluyeron que estas células representaban una población uniforme, capaz de desempeñar una variedad de funciones inmunológicas, incluyendo activación y supresión de la respuesta inmune. De acuerdo con esto, condiciones externas como el tipo de estimulación antigénica, determinaba cual función era expresada por el linfocito $T$ (4). Se planteó que las células $T$ estaban compuestas por subpoblaciones especializadas, cada una equipada para realizar una función particular (5). El problema era encontrar un método para subdividir la población total de linfocitos $T$, en varias subpoblaciones separadas, con funciones diferentes frente a un antígeno determinado.

El primer paso para la identificación y separación de las subpoblaciones de linfocitos $\mathrm{T}$ provino de la observación de que estas células expresaban glicoproteínas en su superficie (6). Moretta en 1976, informó la presencia de receptores de superficie en los linfocitos exclusivos para la porción Fc de la inmunoglobulina $\mathrm{G}$ y de la inmunoglobulina M. Estas dos subpoblaciones fueron denominadas TM (o $\mathrm{T} \mu$ ) y $\mathrm{TG}$ (o $\mathrm{T} \gamma$ ) respectivamente, y se demostró que desempañaban diferentes actividades funcionales in vitro (7.8). De esta forma la subpoblación TM contenía células que promovían la activación de células $\mathrm{B}, \mathrm{y}$ la subpoblación TG tenía actividad supresora sobre las mismas células B (9).

Posteriormente las subpoblaciones de células $T$ se definieron por el uso de antisueros heterólogos, que reconocían antígenos de superficie expresados por los distintos linfocitos T, como $\mathrm{TH}_{1}$ y $\mathrm{TH}_{2}$ (10).

Así pues, aunque la existencia de subpoblaciones fenotípica y funcionalmente diferentes se ha estudiado por algún tiempo, es relativamente reciente, que su cuantificación ha sido posible (11).

En su mayor parte, este progreso es consecuencia de avances tecnológicos importantes.

De primordial importancia fue el desarrollo por Kohler y Millstein, de líneas celulares de hibridoma, lo que inmortalizó la producción de anticuerpos monoclonales $(12,13)$ que ha revolucionado el estudio de la diferenciación de las células $\mathrm{T}$ humanas. También la técnica de flujo microfluorométrico, ha permitido la cuantificación precisa, tanto del número de células que expresan un marcador dado, como la extensión en la cual el marcador es expresado (14). Otro importante avance ha sido la adaptación de condiciones de cultivo, que permiten el crecimiento y mantenimiento de clonas de linfocitos $\mathrm{T}$ durante largo tiempo.

*Médico, Año Servicio Social Obligatorio. Grupo de Microbiología e Inmunología. Instituto Nacional de Salud. 
Combinando estas tecnologías, ha sido posible asignar una capacidad funcional dada a cada subpoblación celular fenotípicamente definida (15). Sin embargo, la heterogeneidad de cada subpoblación, demostrada a nivel clonal, no permite establecer una relación absoluta.

Hasta ahora se han descrito varias glicoproteínas expresadas sobre la membrana celular, que van cambiando a través de la vida del linfocito $T$, estableciendo estados específicos de diferenciación y/o maduración, definiendo tanto subpoblaciones de timocitos como de células $\mathrm{T}$ periféricas $(16,17,18)$.

El objetivo de este trabajo es hacer una revisión de lo que se conoce hasta el momento acerca de las características fenotípicas y funcionales de los linfocitos T, desde su orígen en el timo hasta alcanzar la madurez.

\section{SUBPOBLACIONES DE TIMOCITOS}

Casi dos décadas han pasado, desde que fueron demostradas las consecuencias adversas de la timectomía neonatal sobre la linfopoiesis y la inmunidad (19). Durante los años siguientes se han hecho considerables progresos en la demostración de la importancia del timo en la maduración de los linfocitos $\mathrm{T}$.

En este momento, el timo es considerado como el sitio anatómico primario para la generación de linfocitos inmunocompetentes que se encuentran en sangre y tejidos linfoides periféricos (20.).

La maduración incluye la expresión de receptores específicos de antígeno y la inducción de niveles funcionales de estos receptores de superficie responsables de la función de estas células, la expresión de productos del complejo mayor de histocompatibilidad (MHC) necesarios para la interacción celular específica y la adquisición de funciones tales como cooperadora (helper), citolítica y supresora (4).

El timo en un punto determinado de su desarrollo embriológico comienza a atraer hacia él "stem cells" (o células pluripotenciales). El primer influjo de estas células ocurre alrededor de la octava semana de gestación, y el timo rápidamente se llena de esta población de células progenitoras (21). Se cree que en el adulto el timo recibe continuamente pequeñas cantidades de estas células (20) que van madurando, y establecen varias líneas de diferenciación de linfocitos tímicos.

Es posible identificar tres compartimientos diferentes en el timo humano llamados: subcapsular, cortical y medular. Cada uno de ellos contiene diferentes subpoblaciones de linfocitos y células no linfoides identificadas por una variedad de marcadores de superficie, algunos expresados solamente durante las fases intratímicas de diferenciación, y otras cuya expresión continúa durante toda la vida del linfocito $\mathrm{T}$ (22).

El área subcapsular contiene muchas células blásticas en proliferación que representan aproximadamente el $5 \%$ del total de timocitos (23). La corteza contiene timocitos pequeños que representan la población predominante. En esta región cesa la división celular y la mayoría de estos timocitos mueren dentro del timo (24). En la médula el tipo celular predominante está constituido por linfocitos de tamaño medio. De ella provienen la mayoría de linfocitos $T$ periféricos (25).

La relación precisa entre los timocitos de estas tres regiones no es clara hasta el momento (26). La mayoría de las investigaciones indican que los timocitos pequeños en la corteza se derivan de las células blásticas subcapsulares, pero no existen trabajos concluyentes que indiquen que los timocitos medulares deriven de los timocitos corticales, ya que la mayoría de las células corticales mueren dentro del timo.

Los marcadores de superficie usados para identificar las diferentes subpoblaciones de timocitos definen posiblemente diferentes estados de diferenciación intratímica (16, 27). Estos marcadores son antígenos de superficie indentificados por anticuerpos monoclonales. 
En los primeros estudios hechos en ratones se reconoció el antígeno Theta (28) o Thy-1, que se expresa en el 98\% de los timocitos de ratón. En el humano, un antígeno análogo, denominado T11 (glicoproteína de PM $55 \mathrm{Kd}$ ) se expresa en la mayoría (más del $95 \%$ ) de los timocitos postnatales; está presente en mayor cantidad en la región subcapsular y cortical (29), y continúa expresándose en todas las células $\mathrm{T}$ periféricas. T11 representa el receptor para los eritrocitos de carnero (REC), considerado el marcador más importante para definir las células $\mathrm{T}$ humanas. El antígeno T11 se expresa muy temprano ontogénicamente; sin embargo, muchos timocitos fetales son incapaces de formar rosetas, posiblemente debido a una diferencia cuantitativa en la expresión de este antígeno (30).

El antígeno T1 (o Leu 1), análogo a Lyt-1 en ratones, se expresa en todos los timocitos, aunque en diferente cantidad.

El antígeno T6 (PM $49 \mathrm{Kd}$ ), corresponde a TL en el ratón, y se expresa en el $80 \%$ de los timocitos, especialmente corticales, pero está ausente en los linfocitos de sangre periférica, mientras que T3 (del cual no se ha encontrado equivalente en el ratón), de PM $20 \mathrm{Kd}$, parece que es adquirido relativamente tarde, y se expresa en una pequeña subpoblación de linfocitos (15-30\%), principalmente medulares, pero se encuentra presente en todas las células $\mathrm{T}$ circulantes. Algunos estudios indican que este es el antígeno de mayor importancia encontrado sobre los timocitos humanos, y sobre los linfocitos $T$ periféricos (31), posiblemente debido a que es requerido para la expresión de algunas funciones de las células $\mathrm{T}$ (32).

Los antígenos T9 y T10 todavía no se han reconocido en los timocitos del ratón. T10 (PM $37 \mathrm{Kd}$ ) era considerado como un marcador específico de timocitos; sin embargo, se ha encontrado en una minoría de linfocitos $\mathrm{T}$ periféricos activados. Igualmente T9, considerado también como un marcador presente únicamente en los timocitos, se ha demostrado que representa el receptor para transferrina (33), y que está presente en muchas líneas celulares en división activa.
T8 (Leu2) análogo a Lyt-2 en el ratón, y T4 (Leu3) análogo a L3T4 en el ratón, se expresan en la mayoría de los timocitos (más del $85 \%$ ).

Otros marcadores que se han empleado en la caracterización fenotípica de los timocitos humanos incluyen la enzima deoxinucleotidiltransferasa (TdT), que es una polimerasa DNA encontrada en algunas células precursoras de la línea $\mathrm{T}$ y $\mathrm{B}$. Esta enzima se encuentra principalmente en los timocitos subcapsulares y corticales, pero no en los medulares ni en las células $\mathrm{T}$ periféricas (LTP) (23). PNA "peanut agglutinin" es un marcador de PM $110 \mathrm{Kd}$, restringido a la mayoría de los timocitos corticales y ausente en los timocitos medulares y LTP (34). Todas las células epiteliales tímicas expresan antígenos clase I y clase II del MHC (35). En la corteza las células expresan grandes cantidades de antígenos clase II. En la médula expresan antígeno clase I y II.

Los antígenos clase I de MHC, se expresan también en los timocitos. Los antígenos HLA-A, B y C se encuentran en los timocitos medulares (36). Los antígenos clase II, no se expresan en los timocitos.

La capacidad de los linfocitos $T$ para reconocer los determinantes MHC propios șe relacionan con su interacción con las células epiteliales tímicas que expresan los antígenos $\operatorname{MHC}(37,38)$.

Con base en las proporciones relativas de timocitos que expresan diferentes antígenos de superficie, se ha propuesto un modelo de diferenciación de timocitos humanos (39). (Fig. 1).

Se pueden definir 3 estados principales de diferenciación intratímica: (20).

\section{ESTADO I}

Los timocitos tempranos o jóvenes son representados por una población de células blásticas que constituyen el $5 \%$ de timocitos postnatales, y expresan entre otros, los antígenos T11 y T10. 


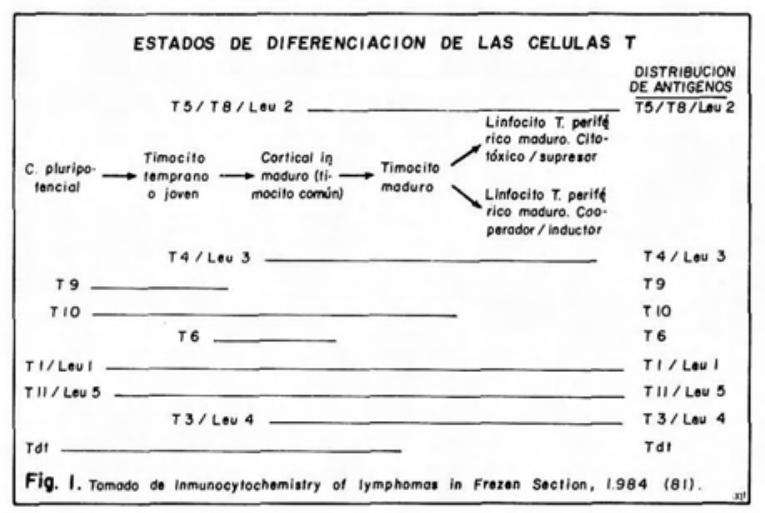

\section{ESTADO II}

Representado por los llamados timocitos comunes, incluyen la mayoría de las células corticales, caracterizadas por la expresión simultánea de los antígenos T4, T8 y T6, además de T11 y T10, y por la pérdida de T9.

\section{ESTADO III}

Representado por los llamados timocitos “maduros", que corresponden a las células medulares y se caracterizan por la fuerte éxpresión de los antígenos clase I del MHC y por el antígeno T3, ausencia de T6, y expresión de los antígenos T4 y T8.

No ha sido posible demostrar la relación de los timocitos maduros con las otras subpoblaciones timocíticas; por lo tanto, no ha podido establecerse la forma exacta mediante la cual se generan las células $\mathrm{T}$ periféricas

\section{SUB-POBLACIONES PERIFERICAS}

Los linfocitos circulan libremente a través de la sangre y vasos linfáticos del cuerpo y son directamente responsables de la respuesta inmune específica (4). El conocimiento existente acerca de los mecanismos de acción de los linfocitos humanos, hace posible considerar varias actividades funcionales asociadas con las células T (40), incluyendo:

1. La actividad "helper" o cooperadora sobre la inducción de la proliferación de las células B y la diferenciación y síntesis de anticuerpos dirigidos contra antígenos timo-dependientes (41).

2. La actividad cooperadora/inductora sobre otras células $\mathrm{T}$, mediante la liberación de interleukina-2 (IL-2) (42).

3. La liberación de linfoquinas que actúan sobre células no linfoides, como los macrófagos y células hematopoyéticas $(43,44)$.

4. La capacidad de actuar como células efectoras citolíticas dirigidas contra células blanco no propias.

5. La capacidad de actuar como células supresoras, regulando la inducción de linfocitos T y B.

La homeostasis inmune resulta de un delicado balance entre las funciones cooperadora y supresora de las células $\mathrm{T}$ humanas (45).

La idea principal entre los inmunólogos es que durante la diferenciación de las células T se producen subpoblaciones exclusivas y funcionalmente diferentes, con marcadores de superficie característicos. Esta idea se originó con los estudios de Boyse y Cantor (46), quienes demostraron que se podían aislar subpoblaciones de células $\mathrm{T}$ de ratón, denominadas Lyt $1+$, Lyt $1+$ y Lyt $3+$, y encontraron que tenían diferentes propiedades funcionales. El marcador Lyt-1, identificaba aquellas células programadas genéticamente para ayudar a inducir la respuesta inmune; los marcadores Lyt2 y Lyt 3 , identificaban aquellas células programadas para desempeñar tanto funciones supresoras como citotóxicas.

Este hallazgo, confirmado por muchos laboratorios, se ha hecho extensivo al análisis de las subpoblaciones de linfocitos $\mathrm{T}$ en humanos principalmente, mediante el uso de anticuerpos monoclonales, que permiten la identificación de las glicoproteínas de superficie que las caracterizan fenotípicamente y están involucradas en los mecanismos de reconocimiento $(10,47)$. 
Los receptores Fc junto con los anticuerpos monoclonales dirigidos contra antígenos de membrana, tienen un valor científico definitivo (48).

La información obtenida por muchos estudios, acerca de la función de los linfocitos como una población, sugiere que las funciones cooperadora y supresora/ citotóxica residen en subpoblaciones fenotípicamente diferentes (49), que representan células diferentes y especializadas.

Estudios funcionales han dado la idea de la existencia de una relación entre la expresión de un marcador dado y su función; sin embargo la función precisa de una célula individual no puede ser invariablemente extrapolada de acuerdo con su fenotipo de superficie (50).

Todas las células $\mathrm{T}$ circulantes expresan los antígenos T1, T3 y T11 (que representa REC). T4 y T8 se expresan cada uno en porcentajes diferentes, y son estos dos marcadores los que definen las subpoblaciones de linfocitos $T$ periféricos (51).

Actualmente se pueden definir dos subpoblaciones mayores de linfocitos $T$ mediante el uso de anticuerpos monoclonales (40).

La primera subpoblación, está determinada por la presencia de un antígeno de superficie de PM de $55 \mathrm{Kd}$, tripsina resistente, llamado T4. Este antígeno es reconocido por los anticuerpos monoclonales OKT4 y anti-Leu3a y se encuentra en aproximadamente el $60 \%$ de las células $\mathrm{T}$ periféricas.

La otra subpoblación expresa una molécula de superficie denominada $T 8$, antígeno compuesto por 2 subunidades de aproximadamente 30 y $45 \mathrm{Kd}$, reconocido por los anticuerpos OKT8, Leu2a y B9.4, y se encuentra aproximadamente en $30 \%$ de LTP.

Las subpoblaciones de linfocitos $\mathrm{T}$ que expresan estos antígenos, $\mathrm{T} 4 \mathrm{y} \mathrm{T} 8$, han sido extensamente estudiadas a nivel de población, y más recientemente a nivel clonal (52). Los estudios hechos a nivel de población indican que la subpolbación T4+ expresa actividad cooperadora/inductora sobre las células T y B, y la subpoblación T8 + está compuesta por células que expresan actividad supresora y citolítica (49). Sin embargo, estudios recientes a nivel clonal, indican heterogeneidad de estas subpoblaciones. Algunas clonas de células $\mathrm{T}$ pueden desarrollar simultáneamente actividad citolítica y cooperadora (52) y algunas clonas T4 + pueden también desarrollar función citolítica.

\section{LINFOCITOS T COOPERADORES/INDUCTORES}

En las primeras investigaciones sobre subpoblaciones de linfocitos $\mathrm{T}$ se estableció que la función cooperadora residía en las células $\mathrm{T} \mu+$, estaba ausente en las células $\mathrm{T} \gamma^{+}$y su función era promover la activación de las células B y la síntesis de anticuerpos, en presencia de "pokeweed-mitogen" (PWM). (53). Estudios posteriores revelaron que la actividad cooperadora podía también ser generada por una pequeña subpoblación de linfocitos $\mathrm{T}$ que carecían de estos receptores $(\mu \gamma)$, y que las células $\mathrm{T} \mu+$ también podían inducir actividad supresora. Posteriormente se informó que la actividad cooperadora estaba confinada a una subpoblación celular que expresaba el antígeno T4, y mediante anticuerpos monoclonales y clonas celulares se demostró que era solamente una proporción de células T4+, las que tenían actividad cooperadora y algunas mostraban actividad supresora y citolítica (54).

La subpoblación de células cooperadoras está compuesta por linfocitos capaces de inducir proliferación y/o diferenciación de otros linfocitos (55).

Se consideran dos clases principales de células $\mathrm{T}$ cooperadoras, unas que actúan sobre otros linfocitos $T$, y otras que regulan las funciones de los linfocitos $B$.

En ambas, la actividad cooperadora es mediada por factores solubles (40). Entre estos, el factor de crecimiento de células $\mathrm{T}$ (FCCT) e interleukina-2 (IL-2), que son liberados por la estimulación antigénica, 
y son requeridos para la proliferación de otras células $\mathrm{T}(56,57)$, tales como linfocitos T citolíticos (LTC) para dar orígen a LTC efectores. Esto, junto con la observación de que la mayor parte de células liberadoras de IL-2 son $\mathrm{T}^{+}$, deja la conclusión de que esta función está asignada a la subpoblación $\mathrm{T}^{+}{ }^{+}$cooperadora (58); sin embargo algunos LTC pueden liberar IL-2 y proliferar en ausencia de células $T$ cooperadoras, coexistiendo así, una función específica en subpoblaciones fenotípicamente diferentes.

La otra función importante es la capacidad de inducir proliferación de cólulas B, y su diferenciación en células secretoras de inmunoglobinas. (4).

Se ha demostrado que las células T cooperadoras producen factores de crecimiento de células B (FCCB), que son capaces de mantener las células B preactivadas, en estados proliferativos.

Otras lifoquinas que promueven la diferenciación final de las células $\mathrm{B}$ son FRT (Factor de reemplazo celular) y FDCB (factor de diferenciación de células B) (40). Heijnen et al, en 1982 informaron que la subpoblación T4 de linfocitos, contiene también células inductoras de supresión, caracterizada por el fenotipo $\mathrm{T}^{+} \mu^{+} \mathrm{Leu}^{+}$ $\mathrm{JRA}^{+} \mathrm{Q} 1^{+}$, definido por anticuerpos monoclonales Leu8 y TQ1, por la sensibilidad de Fc R a la Teofilina, y por los autoanticuerpos encontrados en pacientes con artritis reumatoidea juvenil (JRA) (15).

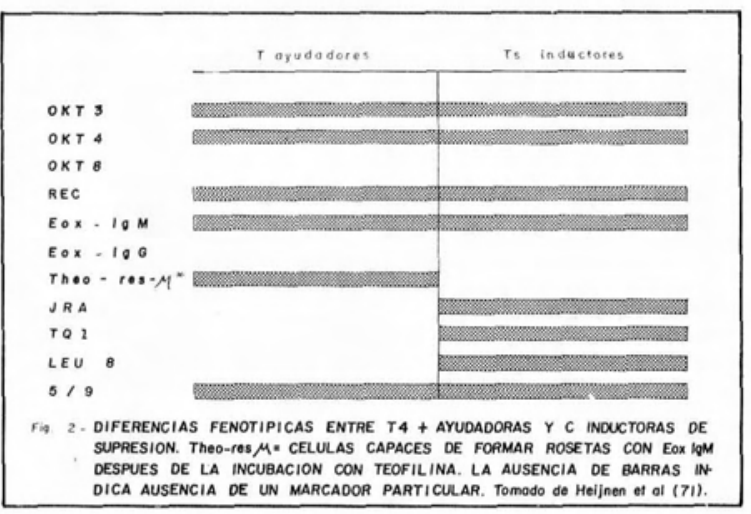

Las características fenotípicas de las células cooperadoras e inductoras de supresión, son resumidas en la Fig. 2.

Esta subpoblación de células inductorss de supresión al ser activadas por un antígeno inducen a la célula $\mathrm{T}$ a diferenciarse en célula $T$ supresora-efectora, que específicamente suprime la función cooperadora.

\section{LINFOCITOS T SUPRESORES Y CITOTOXICOS.}

Estas células desarrollan actividades funcionales diferentes pero para algunos autores son fenotípicamente indistinguibles. La subpoblación $\mathrm{T}^{+}$contiene linfocitos responsables tanto de la actividad citolítica, como de la actividad supresora. Mediante estudios clonales, se ha encontrado que aproximadamente el $30 \%$ de linfocitos $\mathrm{T}$ periféricos, se originan de una progenie citolítica, y la frecuencia de precursores LTC (LTC-P) en la subpoblación $\mathrm{T}^{+}{ }^{+}$, es virtualmente $100 \%$, mientras que fue de 1 en 40 en la subpoblación $\mathrm{T}^{+}(59)$, de tal forma que $\mp$ 90-95\%, y 5-10\% del total de LTC-P fueron $\mathrm{T}^{+}$y $\mathrm{T}^{+}$respectivamente. El hallazgo de que todas las células $\mathrm{T}^{+}{ }^{+}$son LTC-P fue inesperado, ya que esta subpoblación también contiene células supresoras, sugiriendo que posiblemente esta subpoblación contiene muy pocas células supresoras, o que, los LTC tengan también actividad supresora (40).

El nombre de linfocitos cototóxicos, es sinónimo de citolíticos (LTC) y asesinos (Killer) (60). Estas células citolíticas son particularmente importantes en inmunología por su función en transplante de órganos, en la defensa contra virus, parásitos intracelulares, y la respuesta inmune contra tumores $(61,62)$.

Estos linfocitos reconocen antígeno con una exquisita especifidad, en unión con determinantes antígenicos dependientes del MHC (4).

Se han realizado muchos estudios a nivel de población linfocitaria, pero ninguno aporta una información completa y defini- 
tiva acerca de la presencia de marcadores expresados específicamente sobre LTC, si es que hay alguno (40).

Como se mencionó anteriormente, se ha encontrado actividad citolítica en la población $\mathrm{T}_{4}{ }^{+}$, sin embargo, la falla en la detección de esta actividad en cultivo mixto de linfocitos (CML), simplemente refleja la baja frecuencia, más que la ausencia de actividad citolítica en esta población. Además, aunque la mayoría de los LTC parecen estar confinados a la subpoblación $\mathrm{T}^{+}$, el grado de correlación entre la expresión del antígeno T8 y la actividad citolítica todavía no ha sido completamente establecido. Estas limitaciones se relacionan con la ausencia de técnicas apropiadas de dilución para la valoración cuantitativa de los LTC humanos, así como a las dificultades en el mantenimiento y la expansión de LTC en los cultivos contínuos (63).

Muchos estudios se han hecho para definir el fenotipo antigénico de superficie de los LTC utilizando clonas de estos linfocitos, y una batería de marcadores de superficie, incluyendo OKT4 y OKT8. Estos estudios han mostrado que la gran mayoría de las células que expresan esta actividad son $\mathrm{OKT}^{-} \mathrm{OKT} 8^{+}$; $\sin$ embargo, el análisis fenotípico a nivel clonal, ha demostrado una expresión heterogénea del fenotipo OKT en las diferentes subpoblaciones.

La diferenciación entre células inactivas o precursoras (LTC-P), y las células activadas o efectoras, desde el punto de vista fenotípico ha sido difícil de establecer. Algunos autores $(64,65)$ han encontrado la expresión del antígeno HLA-DR, y otro denominado $4 \mathrm{~F} 2$ en LTC activados, y la ausencia de expresión detectable de $\mathrm{Fc}_{\mathrm{C}} \gamma \mathrm{R}$ en estas células.

Importantes progresos se han logrado en el estudio de la función y el fenotipo de LTC después del descubrimiento de un factor soluble denominado FCCT o IL-2, el cual ha permitido un cultivo contínuo, y clonaje de los linfocitos T (42), detectándose tres tipos diferentes de citotoxidad (40):
1. Actividad citolítica específica, selectivamente dirigida hacia células blanco portadoras de los antígenos sensibilizantes.

2. Actividad citotóxica tipo asesinas naturales, dirigidas a algunas células blanco NK-susceptibles.

3. Citotoxicidad celular dependiente de anticuerpos, mediada por células efectoras citolíticas, equipadas con receptores $\mathrm{Fc}_{\mathrm{c}} \gamma$.

Parece haber alguna relación entre la existencia de algunos marcadores de superficie y su actividad citotóxica. Por ejemplo, los LTC $\mathrm{T}^{+}$pudieran ser aquellos que reconocen productos de la clase I de MHC, mientras que los LTC $\mathrm{T}^{+}$, pudieran ser dirigidos contra antígenos clase II de MHC. Estas conclusiones se han basado en que los anticuerpos dirigidos contra determinantes de la clase I y la clase II del MHC, inhiben la acción citolítica de los $\mathrm{LTC} \mathrm{T}^{+}$y $\mathrm{LTC}^{+}{ }^{+}$respectivamente (66).

Se han identificado algunas moléculas de superficie involucradas en la función citolítica. Entre ellas estan T3, T4, T8, previamente mencionadas, $y$ otras como una proteína de $90 \mathrm{Kd}$, denominada $\mathrm{Ti}$, identificada por anticuerpos monoclonales, la cual está constituída por dos subunidades, denominadas $a$ y $\beta$, las cuales posiblemente, hacen parte del receptor de la célula $T$ (18). En los dos últimos años se han descrito otras moléculas; dos de ellas, se han denominado antígenos linfocitarios funcionalmente asociados (LFA 1,2), pues sus correspondientes anticuerpos inhiben la actividad citolítica.

De esta manera, se ha logrado un gran progreso, en cuanto a la determinación de las moléculas que intervienen en la interacción de la célula citolítica con la célula blanco (LTC-C-blanco) (67), tales son la molécula $\mathrm{T} 3$, expresada sobre todos los linfocitos; T4 y T8 unidos a los productos clase II y clase I respectivamente del MHC, y la molécula Ti. 
Un gran número de clonas de LTC humanos se han estudiado, analizando su susceptibilidad a la inhibición mediante anticuerpos monoclonales dirigidos contra T4, T8 y T3,. Estos estudios concluyen que existe heterogeneidad en el requerimiento de estas moléculas para la función citolítica. Con estos estudios ha sido posible construir un modelo hipotético de reconocimiento antígeno por parte del LTC. Se ha sugerido que T8 y T4 pueden actuar como estructuras de reconocimiento asociadas, debido a su unión con las moléculas del MHC, y se considera que sirven, posiblemente, como elementos estabilizadores, que median el contacto necesario para permitir una lisis eficiente por parte del LTC. La estructura responsable de la discriminación del antígeno y su unión, es la molécula $\mathrm{Ti}$, asociada con la glicoproteína T3 (18). Fig. 3.

Los linfocitos $\mathrm{T}$ supresores, poseen propiedades que regulan la respuesta inmune ya que desarrollan una función opuesta a las células T cooperadoras. Entre 1960 y 1970, algunos investigadores observaron que algunas células $T$ jugaban un papel importante en la supresión de la formación de anticuerpos por parte de las células B, mediante la inhibición de la interacción cooperativa de las células $\mathrm{T}$ y las células B. Estas observaciones coinciden con reportes posteriores que sugieren esta misma función y se ha demostrado un mecanismo de retroalimentación interno en el proceso de supresión, que constituye un sistema regulatorio complicado, denominado circuito inmune (4). Dada la complejidad de este sistema, existe mucha controversia acerca del fenotipo y función precisa de estas células.

Como se discutió anteriormente, la subpoblación de linfocitos $\mathrm{T}^{+}$contiene células inductoras de supresión, caracterizadas por el fenotipo $\mathrm{T}^{+} \mu^{+}-$leu8 $+\mathrm{JRA}+\mathrm{TQa}^{+}$. Esta subpoblación celular, al ser activada,

\section{RECEPTORES DE ANTIGENO SOBRE LOS LINFOCITOS T HUMANOS}

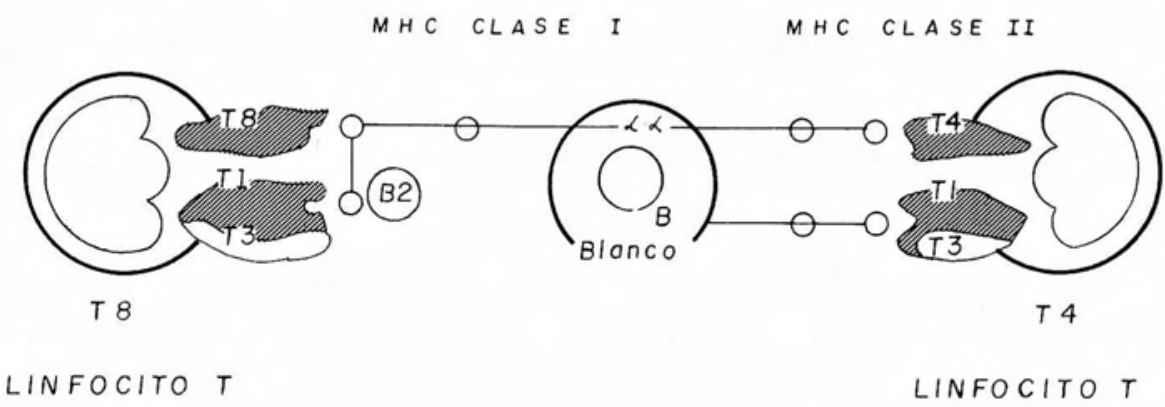

Fig. 3 - Modelo de reconocimiento de antigenos por los linfocitos $T$ humanos. Cada linfocito $T$ posee dos tipos de estructuras para el reconocimiento. Las glicoproteinas T4 y $T 8$, se unen a las regiones no polimórficas de los productos genéticos determinados por MHC clase I y I I respectivamente. T3 y $T 1$ reconocen ontígenos específicos relocionodos con genes polimórficos del MHC.

Tomodo de Mever et al (18) 
induce la producción de células $\mathrm{T}$ supresoras efectoras, las cuales suprimen la función cooperadora.

Esta observación indica la posible existencia de células supresoras precursoras que son inducidas a desarrollar actividad supresora. Estas células precursoras se ha demostrado que pertenecen a la subpoblación $\mathrm{T}^{+}(68,69)$, y que es heterogénea con respecto a los otros determinantes de membranas presentes en las células $\mathrm{T}$ supresoras activadas y efectoras. De tal. forma, que están caracterizadas porque reaccionan exclusivamente con eritrocitos autólogos $\left(\mathrm{Tar}^{+}\right)$, con T8 y T3, y por la ausencia de receptor $F_{c}$ para IgM e IgG $\left(\mathrm{T}^{+} \mathrm{ar}^{+} \mu \gamma^{-}\right)$. Con base en este fenotipo, puede ser distinguida de las otras células supresoras $(70,15)$.

Las células $\mathrm{T}$ supresoras efectoras, son realmente $\mathrm{T}$ debido a que presentan los antígenos de superficie T3 y T8, y expresan el receptor $\mathrm{Fc}_{\mathrm{C}} \gamma \mathrm{R}$, o sea que se +caracterizan por el fenotipo $\mathrm{T}^{+}$ $8^{+} \gamma \mathrm{M}-(71)$.

También se ha concluido que esta subpoblación no solo tiene células supresoras efectoras, sino que también contiene una subpoblación que ante la exposición a un antígeno, activa o amplifica la acción de las células efectoras, sin intervención de las células inductoras de supresión $\mathrm{T}^{+}{ }^{+}$. De tal forma que este grupo particular de células no puede ser clasificado como células precursoras y reciben el nombre de células activadoras de supresión (c. T supressoractivator). Se ha descrito que las células supresoras efectoras pueden ser diferenciadas de las activadoras por el hecho de que las efectoras expresan el determinante HLA-DR sobre su superficie (15), (Fig. 4).

Las células $\mathrm{T}$ supresoras al ser activadas producen un factor denominado TsF120, capaz de inhibir directamente las células $\mathrm{T}$ cooperadoras (72), que en cultivo con células $\mathrm{T}^{+}{ }^{+}$inductoras de supresión, las inhibe, lo que indica un mecanismo de retroalimentación, que parece regular los sistemas celulares ayudador y supresor, en respuesta a un antígeno específico.

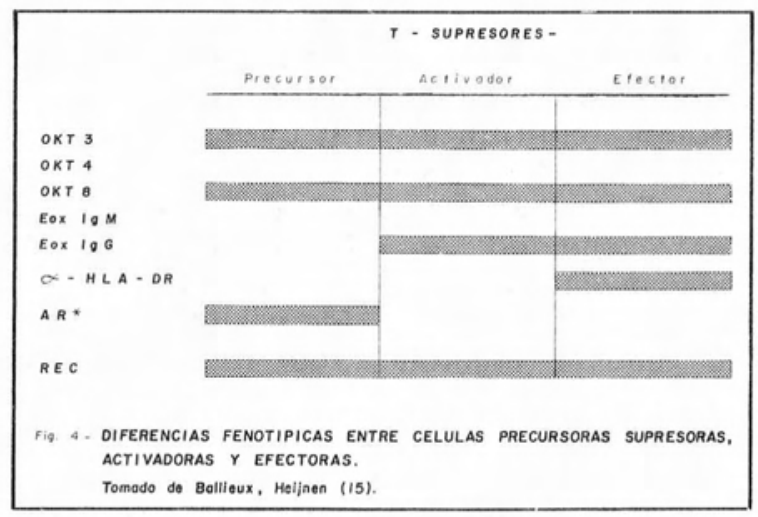

\section{CELULAS ASESINAS NATURALES (Natural Killer)}

Estas células fueron descubiertas hace aproximadamente 10 años (73), durante estudios de citotoxicidad mediada por células en pacientes con tumores observando actividad citotóxica también en linfocitos de individuos normales control. Desde ese momento las células NK han sido ampliamente estudiadas debido a que parece que juegan un papel importante en la resistencia del huésped contra tumores y enfermedades infecciosas $(74,75)$.

Son definidas como "células efectoras con citotoxicidad espontánea rontra varias células blanco, que carecen de las propiedades de un macrófago clásico (M), de un granulocito (PMN) o de un linfocito $T$ citotóxico. La citotoxicidad observada no muestra restricción relacionada con el complejo mayor de histocompatibilidad" (76).

Además estas células no dependen de sensibilización antigénica, y no se ha demostrado una respuesta de memoria secundaria. También se ha demostrado que no son timodependientes, ya que se ha encontrado alta actividad en ratones timectomizados (77).

Actualmente es posible aislarlas como una subpoblación morfológicamente identificada por linfocitos grandes granulares (LGG), que comprende el 5\% de los linfocitos de sangre periférica (78). 
La mayoría, si no toda la actividad NK es mediada por LGG (79); sin embargo, el problema ha sido establecer a qué línea celular específicamente pertenecen. La posibilidad de que provengan de la línea $T$ se basa en la evidencia de que comparten una serie de características con las células $\mathrm{T}$, como algunos marcadores de superficie, su respuesta ante estímulos mitógenos, crecimiento en presencia de IL-2 y la formación de rosetas, pero no se ha demostrado que provengan de esta línea celular, ya que presentan otra serie de características morfológicas y funcionales que las diferencian de los linfocitos $\mathrm{T}$.

También se ha planteado la posibilidad de que se originen de la línea monocítica, o que provengan de una línea separada; sin embargo, ninguna de estas hipótesis ha podido ser comprobada (76).

DISTRIBUCION DE ANTICUERPOS MONOCLONALES

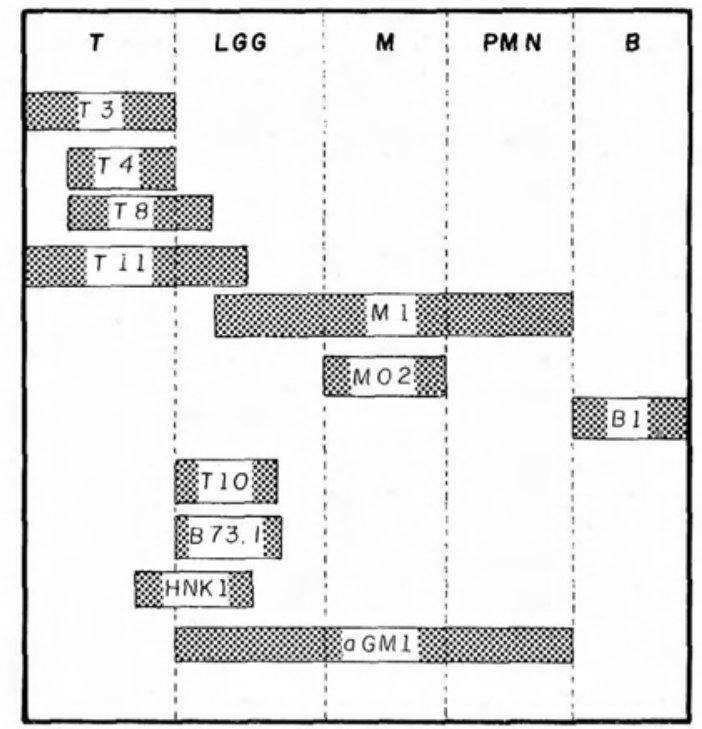

Fig. 5 - PATRONES DE REACTIVIDAD DE VARIOS ANTICUERPOS MONOCLONALES CON LGL $Y$ OTRAS SUBPOBLACIONES.

Tomado de Ortaldo J.R. ef al (76).
El fenotipo de superficie, definido por anticuerpos monoclonales, está representado en la figura 5, en donde se pueden observar las similitudes y diferencias en cuanto a sus marcadores de superficie, comparado con los linfocitos T, macrófagos, polimorfonucleares y linfocitos B. Virtualmente, todas las células NK tienen receptores FcR- $\gamma$ en su superficie, forman rosetas con eritrocitos de carnero, no son adherentes ni fagocíticas, tienen Ig de superficie y característicamente presentan gránulos intracitoplasmáticos que liberan enzimas proteolíticas, mediando así su actividad citotóxica (80). Así pues, aunque no presentan marcadores específicos, si presentan un conjunto propio de receptores que las identifican, constituyendo una población celular claramente definida. Aunque presentan cierto grado de heterogeneidad fenotípica, la mayoría pueden ser descritas como OKT3 ${ }^{-} \mathrm{OKT} 4^{-} \mathrm{OKT} 10+{ }^{+} \mathrm{B} 73.1^{+} \mathrm{OKM}^{+}$. LeuM1 ${ }^{-}$aGM1 ${ }^{+}$. La heterogeneidad comprende solo unos pocos marcadores tales como OKT8, HNK1, OKT11 (76).

La interacción célula NK-célula blanco, depende de la susceptibilidad de la célula blanco y la naturaleza química de esta interacción es desconocida; sin embargo, cuando esto ocurre, hay depósito de unidades líticas en la membrana de la célula blanco, en número suficiente para producir lisis de la membrana celular (80).

\section{BIBLIOGRAFIA}

1. Gowans J.L., Mc Gregor D.D. The immunological activities of lymphocytes. Progr. Allergy. 1965, 9: 1 .

2. Trowell O.A. The lymphocyte. Int. Rev. Cytol. 1958, 7: 235-293.

3. Claman H.N., Chaperon E.A., Triplett R.F. Thymus marrow cell combinations : Synergism in antibody production. Proc. Soc. Exp. Biol. 1966, 122: 1167.

4. William E.P. Fundamental Immunology. Raven Press. 1984.

5. Cantor H., Asofsky R. Sinergy among lymphoid cells mediating the GVH response. J. Exp. Med. 1972, 135: 674 . 
6. Boyse E.A., Old L.J., Stockert E. An approach to the mapping of antigens on $\mathrm{T}$ cell surface. Proc. Natl. Acad. Sci. 1968, 60:886.

7. Moretta L., Ferranini M., Mingari M.C. et al : subpopulations of human $\mathrm{T}$ cells identified by receptors for immunoglobulin and mitogen responsiveness. J. Immunol. 1976, 117: 2171.

8. Moretta L., Mingari M.C., Moretta A. Human $\mathrm{T}$ cell subpopulations in normal and pathologic condition. Immunol Rev. 1979, 45: 163.

9. Moretta L., Webb C., Grossi C.E. et al. Functional analysis of two human T-cell subpopulations : Help and suppression of B-cell response by $\mathrm{T}$ cells bearing receptors for Ig M.J. Exp. Med. 1977, 146: 184.

10. Evans R.L., Breard J.M., Lazarus H., et al. Detection, isolation and functional characterization of two human $\mathrm{T}$ cell subclases bearing unique differentiation antigens. J. Exp. Med. 1977, 145: 221.

11. Mac Donald., Robson H., Moretta L. The definition of lymphocyte subpopulations : New approaches to an old problem. Seminars in Hematology . 1984, 23: 4, 223.

12. Kohler G., Milstein C. Continuous cultures of fused cells secreting antibody of predefined specificity. Nature. 1975, 256: 495-497.

13. Kohler G., Milstein C. Derivation of specific antibody producing tissue culture and tumor line by fusion. Eur. J. Immunol. 1976, 6: 511-519.

14. Herzenber L.A., Sweet R.G., Fluorescenseactivated cell sorting. Scientific American. 1976, 234: 108-118.

15. Ballieux R., Heijnen C. Immunoregulatory $\mathrm{T}$ cell subpopulations in man : Dissection by monoclonal antibodies and Fc-receptors. Immunol. Rev. 1983, 74: 5.

16. Haynes B.F. Human T lymphocyte antigens as defined by monoclonal antibodies. Immunol. Rev. 1981, 57: 127.

17. Haynes B.F., Eisenbarth G.S., Fauci A.J. Human lymphocyte antigens Production of a monoclonal antibody that defines functional thymus derived lymphocyte subsets. Proc. Natl. Acad. Sci. 1979, 76: 5829.

18. Mever S.C., Acuto O., Hercend Th.,Schlossman S., Reinherz E.L. The human T-cell receptor Ann. Rev. Immunol. 1984, 2: 23-50.
19. Miller J.F.A. The thymus. Yesterday, Today and tomorrow - Lancet 1967, 2:1299-1320.

20. Cereding R., Lopez -Botet M., Moretta L. Phenotypic and functional properties of mouse and human thymocytes. Seminars in Hematology. 1984, 21 (4): 244.

21. Le Dovarin N.M., Sotereau F.V. Tracing of cells of the avian thymus throught embryonic life in interspecific chimeras. J. Exp. Med. 1975, 142: $17-40$.

22. Janossy G., Thomas J.A., Bollum F.J. et al. The human thymic microenviroment : An immunohistological study J. Immunol. 1980, 125: 202-212.

23. Bodger M.P., Janossy G., Bollum F.J. et al : The ontogeny of terminal deoxinucleotidyl transferase positive cells in the human fetus. Blood. 1983, 61:1125-1131.

24. Tridente G. Immunopathology of the human thymus. Seminars in Hematology. 1985, 22 (1): 56-57.

25. Scollay R. Thymus cell migration : Cells migrating from the thymus to peripheral lymphoid organs have a "mature" phenotype. J. Immunol, 1982, 128: 1566.

26. Durkin H.G., Carboni J.M., Waksman B. Antigen induced increase in migration of large cortical thymocytes to the marginal zone and red pulp of the spleen. J. Immunol. 1978, 121: $1075-1081$.

27. Reinherz E.L., Kung P.C., Goldstein G et al. Discrete stages of human intrathymic differentiation: Analysis of normal thymocites and leukemia lymphoblasts of T-cell lineage. Proc. Natl. Acad. Sci. 1980, 77: 1588-1592.

28. Moore M.A.S., Owen J.J.T. Experimental studies on the development of the thymus. J. Exp. Med. 1967, 126: 715-726.

29. Tidman N., Janossy G., Bodger M. et al : Delineation of human thymocyte differentiation pathways utilizing double staining techniques with monoclonal antibodies. Clin. Exp. Immunol. 1981, 45: 457-467.

30. Verbi W., Greaves M.F., Koubek K., et al : OKT11 and OKT11 A : Monoclonal antibodies with pan-T reactivity which block sheep erythrocyte receptors on $\mathrm{T}$ cells. Eur. J. Immunol. 1982, 12: 81-86. 
31. Kung P.C., Goldstein G., Reinherz E.L. et al : Monoclonal antibodies defining distinctive human T-cell surface antigens. Science. 1979, 206: 347-349.

32. Hayward A.R., Kurnick J.T., Clarke D.R. T cell growth factor enhanced PHA response of human thymus cells : Requierement for T3 cells. J. Immunol. 1981, 127: 2079-2082.

33. Trowbridge I.S., Omary M.B. Human cell surface glycoprotein related to cell proliferation is the receptor for transferin. Proc. Natl. Acad. Sci. 1981, 78: 3039-3043.

34. Berrih S., Boussuges C., Binet J.P. et al. Studies on human thymocytes using anti-T cell monoclonal antibodies and peanut agglutinin. Cell Immunol. 1982, 74: 260-268.

35. Accolla R.S., Moretta A., Carres S. The human Ia system. An overview. Seminars Hematol. 1984, 21: 287.

36. Cereding R.H., Glasebrook A.L., Mac Donald H.R. Phenotypic and functional properties of murine thymocites. J. Exp. Med. 1982, 155: 358-379.

37. Bhan A.K., Reinherz E.L., Popperna S. et al. Location of T cell and major histocompatibility complex antigen in the human thymus. J. Exp. Med. 1980, 152: 771-782.

38. Mitsrya H., Matis L.A., Megson M. et al. Generation of an HLA-restricted cytotoxic T-cell line reactive against cultured tumor cells from a patient infected with human $\mathrm{T}$ cell leukemia/lymphoma virus. J. Exp. Med. 1983, 158: 994-999.

39. Reinherz E.L., Schlossman S.F. Human T-lymphocyte differentiation. Inmunol today. 1982, 3: 239-240.

40. Moretta A., Pantaleo G., Maggi E., Mingari M.C. Recent advances in the phenotypic and functional analysis of human T lymphocytes. Seminars in Hematology. 1984, 21 (4): 257-269.

41. Fauci A.S. Human B Lymphocyte function : Cell triggering and immunoregulation. $\mathrm{J}$. Infect. Dis. 1982, 145: 602 .

42. Moller G (ed) T cell stimulating growth factors. Immunol Rev. 1980, 51.

43. Burguess A.W. Metcalf D. The nature and action of granulocyte - macrophage colony stimulating factors. Blood. 1980, 56: 947.
44. Watson J.D., Prestidge R.L. Interleukin 3 and colony stimulating factors. Immunology today. 1983, 4: 278.

45. Thomas Y., Bogozinsky L., Irigoyen D., Kung P.C. Functional analysis of human $\mathrm{T}$ cell subsets defined by monoclonal antibodies. J. Exp. Med. 1981, 154: 459.

46. Cantor H., Boyse E.A. Functional subclasses of T lymphocytes bearing different Ly antigens generation of functionally distinct $T$ cell subclasses in a differentiative process independent of antigen. J. Exp. Med. 1975, 141: 1376.

47. Reinherz E.L. Mever S.C. y Schlossman S. The human $\mathrm{T}$ cell receptor : Analysis with cytotoxic $\mathrm{T}$ cell clones. Immunol Rev. 1983, 74: 83.

48. Moretta L., Mingari M.C., Sekaly P.R., Moretta A., Chapnis B. y Cerottini J.C. Surface markers of cloned human T cells with various cytolytic activities. J. Exp. Med. 1981, 154: 569.

49. Reinherz E.L., Schlossman S.F. The differentiation and function of human $\mathrm{T}$ lymphocyte. Cell. 1980, 19: 821.

50. Moretta L., Mingari M.C., Moretta A., Fauci A. Human lymphocyte surface markersSeminars in Hematology 19(4): 273-283, 1982.

51. Reinherz E., Schlossman S. Regulation of the immune response. Inducer and suppressor T-lymphocyte subsets in human beings. New Eng. J. Med. 1980, 303 (7): 370-373.

52. Fathman C.G., Frelinger J. T-lymphocyte clones.Ann. Rev. Immunol. 1983, 1: 633-55.

53. Heijnen C.J., Vytde Haag., Gmelig-Meylig. Ballieux Human B cell activation in vitro. Cell Immunol. 1979, 43: 282.

54. Mingari M.C., Meliodi G., Moretta A. et al. Surface markers of cloned human T cells with helper or suppressor activity on pokeweedmitogen driven B Cell differentiation. Eur. J. Immunol. 1982, 12: 900.

55. Ely J.M., Prystowsky M.B., Eisenberg L. et al. Alloreactive cloned $\mathrm{T}$ cell lines. Differential kinetics of IL-2, CSF and BCSF release by a cloned $\mathrm{T}$ amplifier cell and its variant. $\mathrm{J}$. Immunol. 1981, 127: 2345.

56. Gillis S.A., Gillis E. Henney C.S. Monoclonal antibody directed against interleukin 2 (IL2) $\mathrm{J}$. Exp. Med. 1981, 154: 983. 
57. Kern D.E., Gillis S.A., Okada M. et al. The role of interleukin 2 (IL2) in the differentiation of citotoxic $\mathrm{T}$ cell. J. Immunol. 1:81, 127: 1323.

58. Mever S.C., Hussey R.E., Penta et al. Cellular origin of interleukin 2 in man: Evidence for stimulus-restricted IL2 production by $\mathrm{T}^{+}$an T8+ lymphocytes. J. Immunol. 1982, 129: 1076.

59. Moretta A., Pantaleo G., Moretta L., et al. Cuantitative assessment of the pool size and subset distribution of cytolytic $\mathrm{T}$ lymphocytes within human resting or alloactivated peripheral blood T cell populations J. Exp. Med. 1983, 158: 571.

60. Benacerraf B. Unchue E. textbook of Immunology Baltimore. Williams and Wilkins. 1979, pp. 93 .

61. Lin Y., Askonas B.A. Biological properties of an influenza A virus-specific Killer $\mathrm{T}$ cell. Clone inhibition of virus replication in vivo and induction of delayed-type hipersensitivity reactions. J. Exp. Med. 1981, 154: 225.

62. Engers H.D., Glasebrook A.L., Sorenson G.D. Allogenic tumor rejection induced by the intravenous injection of Lyt-2 $^{+}$cytolytic $\mathrm{T}$ lymphocytes clones J. Exp. Med. 1980, 156.

63. Miller R.G., Teh H.S., Herley E. et al : Quantitative studies of the activation of cytotoxic lymphocyte precursor cells.Immunol. Rev. 1977, 35: 38.

64. Moretta A. Mingari M.C., Haynes B.F. et al Phenotypic characterization of human cytolytic T lymphocytes generated in mixed lymphocyte culture. J. Exp. Med. 1981, 153; 213-218.

65. Eisenbarth G.S., Haynes B.F., Schroer J.A. et al. Production of monoclonal antibodies reacting with peripheral blood mononuclear cell surface differentiation antigens. J. Immunol. 1980, 124: 1237.

66. Biddison W.E., Rao P.E., Talle M.A. et al. Possible involvement of the OKT4 molecule in T cell recognition of class II HLA antigens : Evidence from studies of cytotoxic T lymphocytes specific for SB antigens. J. Exp. Med. 1982, 156: 1065 .

67. Martz E., Heagy W., Gromkowski S. The mecanism of CTL - mediated filling. Monoclonal antibody analysis of the roles of killer and target cell membrane proteins. Immunol Rev. 1983, 72: 73 .

68. Morimoto C., Distazo J.A., Borel Y., Schlossman S.F., Reinherz E.L. Communicative interactions between suopopulations of human $\mathrm{T}$ lymphocytes required for generation of suppressor effector function in a primary antibody response. J. Immunol. 1982, 128: 1645.

69. Thomas Y., Sosman J., Irigoyen O., Friedman S.M., Kung P.C., Goldstein G., Chess L. Functional analysis of human $\mathrm{T}$ subsets defined by monoclonal antibodies I. Collaborative T-T interactions in the immunoregulation of $\mathrm{B}$ cell differentiation. J. Immunol. 1980, 125: 2402.

70. Palacios R., Alarcon-Segovia D., Llorente L., Ruiz Arguielles, Diaz-SE. Human post-thymic precursor cells in health and disease. Characterization of the autologous rosetteforming $\mathrm{T}$ cells as post-thymic precursors. Immunology. 1981, 42: 127.

71. Heijnen C.J., Pot K.H., Ballieux R.E. Characterization of human $\mathrm{T}$ suppressorinducer, precursor and effector lymphocytes in the antigen-specific plaque forming cell response. Eur. J. Immunol. 1982, 12: 860.

72. Vyte Haag F., Heijnen C.J., Pot K.H., Ballieux R.E. Antigen-specific human $\mathrm{T}$ cell factors. T cell suppressor factor : biologic properties. J. Immunol. 1981, 126: 503.

73. Kiesseling R., Klein E., Wigzell H. Natural Killer cells in mouse. Cytotoxic cells with specificity for mouse moloney leukemic cells. Specificity and distribution according to genotype. Eur. J. Immunol. 1975, 5: 112.

74. Hanna N., Burton R. Definitive evidence that natural Killer (NK) cells inhibit experimental tumor metastasis in vivo. J. Immunol. 1981, 127: 1754 .

75. Herberman R.B., Ortaldo J.R. Natural Killer cells. Their role in defenses against diseases. Science. 1981, 214: 24.

76. Ortaldo J.R., Herberman R. Heterogeneity of Natural Killer cells. Ann. Rev. Immunol. 1984, 2: 359-394.

77. Cantor H., Kasai M., Shen H.W., Le Clerc J.C., Glimcher L. Immunogenetic analysis of natural Killer activity in the mouse. Immunol. 1979, 44: 1 . 
SUBPOBLACIONES DE LINFOCITOS T.

78. Kumugci K., Itoh K., Suzuki R., Hinuma S., Saitoh F. Natural Killer (NK) cell activity in the rat. Isolation and characterization of the effector cells. J. Immunol. 1981, 127: 282.

79. Timonen T., Ortaldo J.R., Herberman R.B. Characteristics of human large lymphocytes and relation-ship to natural killer cells. J. Exp. Med. 1981, 153: 569.
80. Trinchieri G., Perossia B. Biology of disease. Human natural killer cells: Biologic and pathologic aspects. Laboratory investigation. 1984, 50. (5): 489.

81. Tubbs R. Immunocytochemistry of Lymphomas in frozen sections. Immunocytochemistry workshop in tumor diagnosis. Part I, October, 1984. Editorial the University of Rochester Rochester, New York. 